\title{
Expressão citofotométrica do fator de proliferação celular ki-67 no bócio colóide e no carcinoma papilífero da tireóide
}

\author{
Citophotometric expression of the factor of cellular proliferation ki-67 in the \\ goiter colloid and in the papillary carcinoma of the thyroid
}

Gleim Dias de Souza ${ }^{1}$; Nicolau Gregori Czeczko, TCBC-PR²; Hamilton Moreira²; Jurandir Marcondes Ribas Filho, TCBC-PR²; Osvaldo Mafafaia, TCBC-PR²; Leticia Elizabeth Augustin CzeCzko3; Edilson Schwansee Thiele ${ }^{4}$; Luiz Roberto Farion de Aguiar ${ }^{4}$

\section{RES U M O}

\begin{abstract}
Objetivo: Comparar a expressão citofotométrica quantitativa do fator de proliferação celular Ki-67 no bócio colóide com o do carcinoma papilífero da tireóide. Métodos: Foram estudadas a expressão da proteína Ki-67, em 12 casos de bócio colóide da tireóide e 20 casos de carcinoma papilífero da tireóide. Os núcleos celulares imunomarcados foram quantificados através do software SAMBA $4000 \AA$ e do software IMMUNO ${ }^{\circ}$, analisando o índice de marcagem e densidade óptica. Foi estimado o coeficiente de correlação de Spearmane e o teste não-paramétrico de Mann-Whitney. Resultados: Foi rejeitada a hipótese nula para o índice de marcagem. confirmando que existe diferença significativa entre o bócio colóide e o carcinoma papilífero da tireóide, quanto ao índice de marcagem do Ki-67, que são maiores nos carcinomas papilíferos da tireóide. Não foi encontrada diferença quanto à densidade óptica. Quanto ao bócio colóide, o coeficiente de correlação estimado entre o índice de marcagem e a densidade óptica do Ki-67 foi igual a 0,78. No bócio colóide, houve associação positiva e significativa entre o índice de marcagem e a densidade ótica do Ki-67. Para o carcinoma papilífero da tireóide o coeficiente de correlação estimado entre o índice de marcagem e a densidade ótica do Ki-67 foi igual a 0,18. Não houve no carcinoma papilífero de tireóide, associação entre o índice de marcagem e a densidade ótica do Ki-67. Conclusão: A expressão citofotométrica do Ki67 no bócio colóide teve índice médio de marcação de 13,92\% e densidade óptica média de 36,43; a expressão citofotométrica do Ki-67 no carcinoma papilífero teve índice médio de marcação de 38,29\% e densidade óptica média de 48,07\%; há maior proliferação celular no carcinoma papilífero em comparação com o bócio colóide na expressão do Ki-67.
\end{abstract}

Descritores: Imunoistoquímica. Proliferação celular. Bócio nodular. Neoplasias da glândula tireóide.

\section{INTRODUÇÃO}

$\mathrm{O}$ desenvolvimento e formação de uma neoplasia é consequência de uma série de alterações no genoma celular. Há envolvimento da inativação de genes supressores tumorais e a ativação de proto-oncogenes. Por conseguinte, cada tipo de célula do corpo humano, apresenta sensibilidade e especificidade diferentes a fatores intrínsecos e extrínsecos no desencadeamento da formação dos tumores.

A agressividade dos tumores tireoideanos pode ser demonstrada através da atividade proliferativa de suas células. C-MYC, Ki-67 e PCNA são proteínas nucleares envolvidas na regulação da proliferação celular. O Ki-67 e o PCNA são marcadores localizados no núcleo celular e são bastante utilizados para identificar células em proliferação, normalmente em conjunto com outros oncogenes. O anticorpo monoclonal Ki-67 detecta uma proteína nuclear. Este anticorpo, marca núcleos das células em diferentes fases do ciclo celular (fase G1, S, G2 e M), mas não marcam as em quiescência (G0). Já foi tentada a utilização isolada deste marcador no carcinoma de tireóide, onde revelou que sua expressão está aumentada, e também o Ki67 foi associado em investigação com p53'.

A quantificação da proteína Ki-67 é um dos mais comuns ensaios realizados para o mensuração da fração das células tumorais que estão em crescimento. A detecção de Ki-67 é feita em biópsias e tem como principal objetivo determinar a porcentagem das células tumorais que estão se dividindo e dando origem a mais células cancerígenas. Esta informação é de grande importância no momento de se decidir qual é o melhor tratamento ao qual o paciente deve ser submetido. A análise da quantificação da proteína Ki-67 é feita por patologista utilizando técnicas específicas de imunoistoquímica, que envolvem a preparação de secções histológicas, juntamente com incubação com um anticorpo que reage com a molécula Ki-67 (denominado de MIB-1). Por sua vez ele está ligado com outras molécu-

Estudo realizado no Programa de Pós-Graduação em Princípios da Cirurgia da Faculdade Evangélica do Paraná em Curitiba/Hospital Universitário Evangélico de Curitiba - FEPAR/HUEC, Curitiba, PR, Brasil.

1. Professor da Universidade Católica de Brasília, Brasília, DF, Brasil, BR; 2. Professor Permanente do Programa de Pós-Graduação em Princípios da Cirurgia da FEPAR/HUEC - PR - BR; 3. Aluna de iniciação científica do Programa de Pós-Graduação em Princípios da Cirurgia da FEPAR/HUEC - PR - BR; 4. Mestre do Programa de Pós-Graduação em Princípios da Cirurgia. 
las que apresentam colorações diferentes dependendo do meio em que se encontram. Desta forma, o patologista, com o auxílio de um microscópio, pode determinar a fração das células que se encontram em crescimento ativo, comparando a número de núcleos marcados, isto é, que apresentam grande quantidade da proteína Ki-67².

Este estudo tem por objetivo comparar a expressão citofotométrica quantitativa do fator de proliferação celular Ki-67 no bócio colóide com o do carcinoma papilífero da tireóide.

\section{MÉTODOS}

A amostra inicial foi composta de 60 blocos de parafina, sendo 30 com tecido de bócio colóide da tireóide e 30 com carcinoma papilífero. Foi realizada análise qualitativa dos blocos sendo excluídos os que tinham defeitos de fixação, contaminação por fungos, alto percentual de necrose e diagnóstico inconclusivo. Esta análise foi realizada por dois patologistas, através de avaliação macroscópica e microscópica.

Realizada a avaliação da amostra inicial, houve eliminação de 28 blocos. Constituiu-se assim a amostra definitiva em 32 blocos de parafina, sendo 20 de bócio colóide e 12 de carcinoma papilífero.

Para realização da pesquisa os blocos foram cortados em micrótomo rotativo, onde foram obtidos cortes histológicos de cinco micra de espessura e foram preparadas duas novas lâminas de cada um dos 32 blocos. Foram coradas pela técnica convencional de hematoxilina-eosina e específica para imunoistoquímica no estudo do Ki-67.

Após coradas por hematoxilina-eosina, as lâminas foram submetidas à avaliação histopatológica por médico patologista, para validação dos diagnósticos previamente estabelecidos no serviço de origem. Utilizou-se microscópio óptico NIKON® e as lâminas foram visualizadas no aumento de 100 até 1000 aumentos. Foram confirmados os diagnósticos de 20 casos de bócio colóide e 12 de carcinoma papilífero e a seguir confeccionadas novas lâminas para análise imunoistoquímica.

No preparo das lâminas para o estudo de imunoistoquímico, o tempo gasto para a coloração foi de 48 horas, seguindo-se a técnica usual de confecção.

O anticorpo primário denominado Ki-67Dakocytomation/USA-Clone/Klon MIB-1@ código M700 L (monoclonal) Ki-67 foi utilizado, diluindo-se $1 \mathrm{~mL}$ de Ki-67 para $100 \mathrm{~mL}$ do diluente.

Utilizou-se o sistema SAMBA 4000® (Systeme d"Analyse Microscopique á Balayage Automática) Sistema de Análise Microscópica de Busca Automática, desenvolvido pela Alcatel (Grenoble-França) para a análise da imagem.

O fluxo de luz proveniente da lâmpada de xenônio do microscópio é controlado por um potenciômetro capaz de medir com precisão a quantidade que passa. Este feixe atravessa a lâmina histológica e a objetiva em uso. A seguir é divido em duas partes: uma para observação visual do pesquisador e outra para captação da imagem por câmara de vídeo que a remete ao computador acoplado e seu monitor.

O computador importa as imagens da câmara de vídeo e executa a interpretação pelo software IMMUNO®. Antes de utilizá-lo, o software é calibrado.

As imagens, analógicas na sua concepção, são captadas através da câmara e transformadas em representações numéricas com a finalidade de transformar as imagens coradas pelo marcador Ki-67 em uma matriz numérica. A partir de então, são calculados os parâmetros matemáticos que permitem a análise das imagens microscópicas.

A luz absorvida pelo tecido é quantificada e expressa através de uma escala de variações de níveis de cinza que varia de 0 (preto) a 255 ( branco). Este processo envolve duas etapas: geração de matriz em níveis de cinza e a transformação em matriz numérica binária.

Ao utilizar o software IMMUNO® analisou-se duas variáveis que irão caracterizar quantitativamente as reações de coloração imunoistoquímicas específicas para a pesquisa: índice de marcagem e densidade óptica média.

O índice de marcagem descreve a porcentagem de área tecidual marcada pela imunoistoquímica. A densidade óptica média reflete a intensidade de marcação. A análise foi realizada em dez campos histológicos.

No intuito de realizar a padronização do sistema para a análise microscópica computadorizada, foi utilizada uma lâmina histológica considerada controle negativo, da qual o anticorpo anti-Ki-67 foi omitido, que foi analisada para cada um dos parâmetros acima mencionados.

Os testes para análise e estatística foram realizados com os parâmetros emitidos pelo próprio software do sistema. A representação das variáveis calculadas pela quantificação do marcador imunoistoquímico, através da imagem computadorizada permite observar a área da superfície analisada e a intensidade de marcação.

Foi utilizado o teste de Spearman para a análise de correlação dos resultados. A correlação mede o grau de associação entre duas variáveis, o seu valor, que varia de 1 a 1, indica a direção e a intensidade da relação entre as duas variáveis, sendo que os valores próximos a 1 mostram associação forte e positiva, ou seja o aumento de um acompanha o aumento do outro. Já valor próximo a -1 indica associação negativa, referindo que o aumento de um implica na diminuição do outro. Com a medida, foi então realizado teste de significância, cuja hipótese inicial é de que não existe associação entre as variáveis. Valores de $p$ menores que 0,05 indicavam associação significativa. Foram utilizados os seguintes dados para análise: média, mediana, valores mínimos, valores máximos e desvios-padrão das variáveis analisadas por doença e o p-valor, com os testes de Mann-Whitney e Shapiro-Wil.

\section{RESULTADOS}

A média do índice de marcação nos 20 casos estudados foi de 13,92\%, e a da densidade óptica de 36,43 . Os campos lidos variaram de 5 a 10 em função da quantidade de material apresentada em cada lâmina. 
A figura 1 demonstra a frequência de normalidade apresentada pelo índice de marcagem no bócio colóide, maior nos intervalos 0 (35\%), e de 0,1 a 20 (40\%).

A figura 2 explicita a frequência de normalidade apresentada pela densidade óptica no bócio colóide, maior nos intervalos 0 (35\%) e de 50,1 a 75 (30\%).

A média do índice de marcação nos 12 casos de carcinoma papilífero estudados foi de $38,29 \%$ e a da densidade óptica de 48,07. Os campos lidos variaram de 3 a 10 em função da quantidade de tecido tumoral apresentada em cada lâmina.

A figura 3 mostra a frequência de normalidade apresentada pelo índice marcagem no carcinoma papilífero, com maior frequência nos intervalos de 20,1 a 40 (41,67\%) e de 40,1 a 60 (41,67\%).

A figura 4 demonstra a frequência de normalidade apresentada pela densidade óptica no carcinoma papilífero, maior nos intervalos de 45,1 a 50 (50\%) e de 50,1 a 55 (25\%).

A expressão comparativa do índice de marcagem pelo Ki-67 entre o bócio colóide e o carcinoma evidenciou diferença estatisticamente significativa com $p<0,001$. Não houve diferença significativa entre a densidade óptica $(p=0,454)$ (Figuras 5 e 6$)$.

Para o bócio colóide, o coeficiente de correlação entre o índice de marcagem e a densidade ótica do Ki-67 foi igual a 0,78, com diferença significativa $(p<0,001$ teste de Sperman).

Para o carcinoma papilífero, o coeficiente de correlação entre o índice de marcagem e a densidade ótica do Ki-67 foi igual a 0,18. O resultado do teste Sperman foi de $p=0,572$.

\section{DISCUSSÃO}

A motivação para que essa pesquisa fosse realizada para avaliar a expressão do Ki-67 no bócio colóide e carcinoma papilífero da tireóide, foi pela existência de um número reduzido de trabalhos sobre o assunto.

O bócio colóide e o carcinoma papilífero da tireóide são as doenças benigna e maligna mais frequentes da glândula tireóide. O bócio colóide apresenta poucas diferenças histológicas com o tecido tiroideano normal, ocorrendo em aproximadamente $4 \%$ da população. Já o carcinoma papilífero é um tipo de tumor que se apresenta com diagnóstico difícil, ocorrendo em $2 \%$ da população.

A detecção da atividade proliferativa celular é importante ferramenta de análise para o acompanhamento do curso clínico, tratamento e prognóstico, sendo que a análise da imunomarcação pelo Ki-67 vem sendo estudada há poucos anos na tireóide 3 .

Análises do ciclo celular revelaram que a proteína Ki-67 é um antígeno associado à proliferação, que é expresso em todas as partes ativas do ciclo celular (G1, S, G2 e M), mas é ausente no descanso celular (G0). Anticorpos contra a proteína Ki-67, no entanto, foram usados em numerosos estudos de importância prognóstica de mensuração de proliferação celular em amostras clínicas de neoplasias humanas. Foram provadas recentemente as evidências de que toda regulação da expressão da proteína Ki-67 é acompanhada por modificações pós-traducionais que ocorrem em específicos pontos de checagem que governam a progressão do ciclo celular. Estas modificações

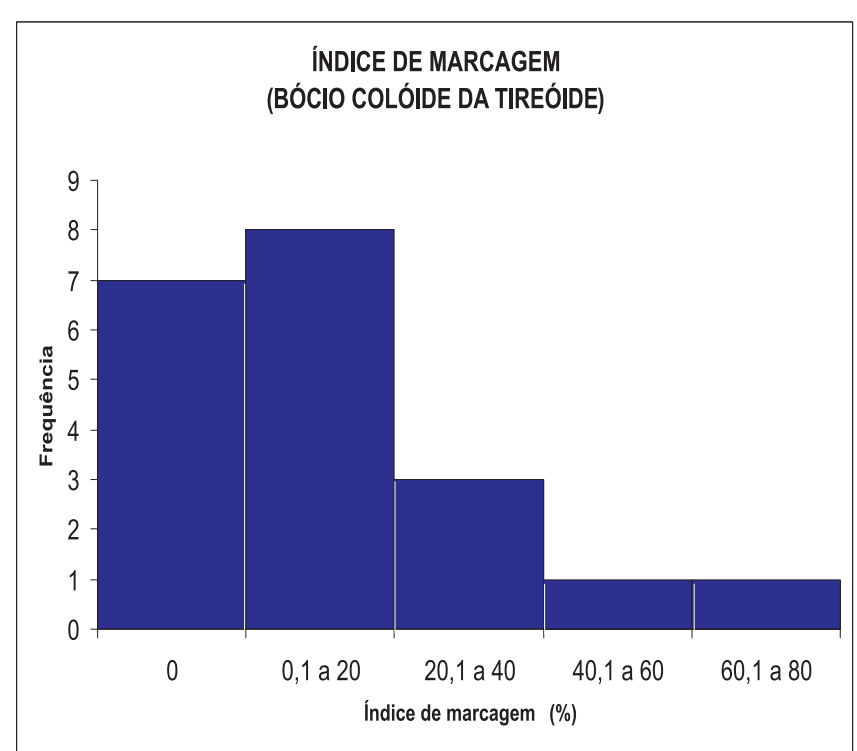

Figura 1 - Frequências do índice de marcagem para o bócio colóide.

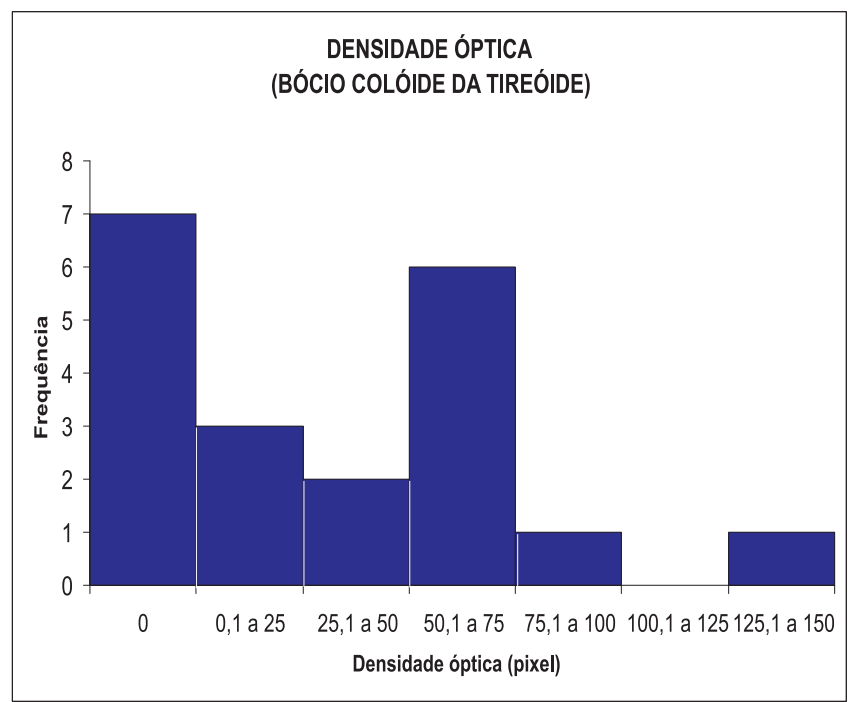

Figura 2 - Frequências da densidade óptica para o bócio colóide.

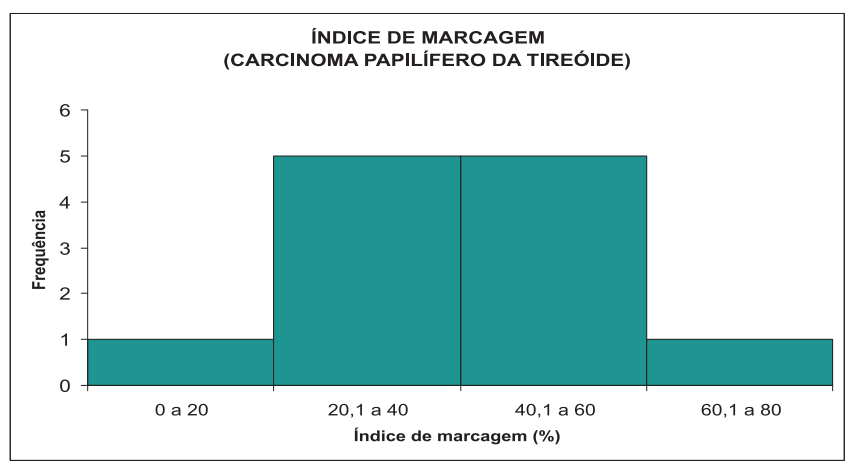

Figura 3 - $\quad$ Frequências do índice de marcagem para o carcinoma papilífero. 


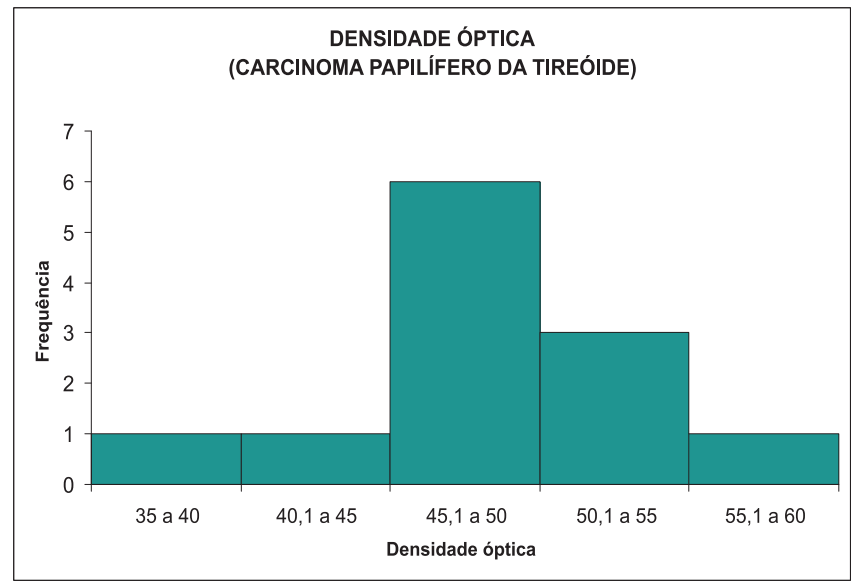

Figura 4 - Frequências da densidade óptica no carcinoma papilifero.

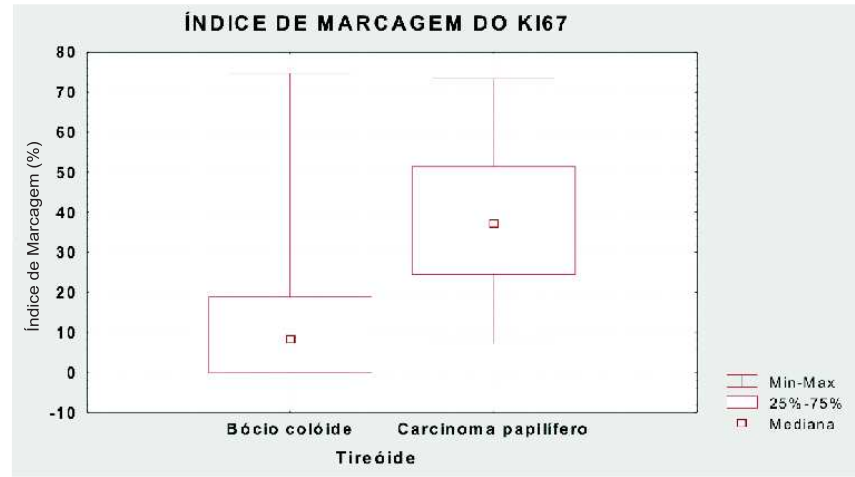

Figura 5 - $\quad$ Comparação entre índice de margem do bócio colóide e o do carcinoma papilífero.

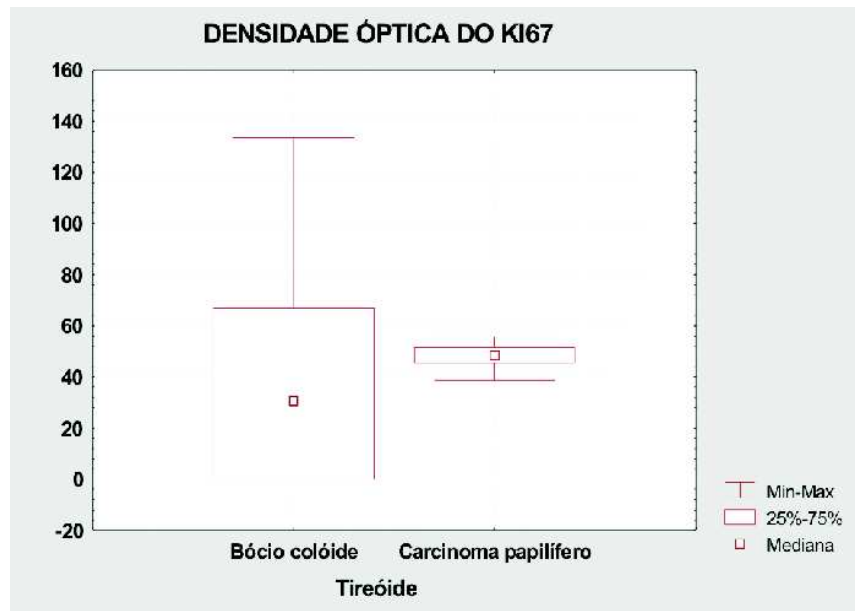

Figura 6 - Comparação entre a densidade óptica do bócio colóide e o carcinoma papilífero.

são causadas pela fosforilação ciclo-dependente da proteína Ki-67 e é intimamente acoplada a parada no núcleo durante a mitose, revertida quando a separação das cromátides irmãs é finalizada. A fosforilação da proteína Ki-67 depende da presença de cdc2 que é a quinase reguladora chave que controla a entrada e a duração da mitose. A proteína Ki-67 é da família das proteínas sensíveis a anticorpos MPM-2, que possuem um fosfo-epitopo conservado durante a evolução².
No trabalho desenvolvido ocorreu maior resposta proliferativa no carcinoma papilífero da tireóide do que no bócio colóide. Algumas limitações do estudo se referem ao próprio marcador, pois apesar de ser indiscutivelmente um marcador de proliferação celular, a sua função fisiológica durante a divisão celular ainda permanece desconhecida. Uma célula pode ser positiva para o Ki-67 mesmo que ela não esteja em proliferação, porém esta célula vai se dividir. Este evento celular então, não se refere ao estado atual da célula, mas a um evento futuro. Mesmo se a síntese de DNA seja bloqueada, a célula continua a expressar Ki-67 para manter o potencial proliferativo, assim quando o bloqueio for interrompido, dano reparado, ela estará pronta para entrar em proliferação ${ }^{4}$. Além disso, alguns autores postulam que uma célula pode entrar em quiescência mesmo depois de completar a síntese de DNA fase $S^{5}$, o que pode corroborar a idéia descrita acima. Por isso os autores advertem para o uso do marcador Ki-67 em tecidos onde a proteína p53 está presente em grandes concentrações ${ }^{4}$.

O anticorpo monoclonal Ki-67 detecta uma proteína nuclear que deriva de camundongos imunizados com o núcleo da linhagem celular $\mathrm{L} 428^{4}$. Este anticorpo marca núcleos das células em diferentes fases do ciclo celular (fase G1, S, G2 e M), mas não marcam aqueles em quiescência (G0). Além da tentativa de utilização isolada deste marcador nos carcinomas de tireóide, onde a expressão está aumentada, o Ki-67 foi utilizado em conjunto com a investigação de $p 53^{5}$ onde se obteve resultado semelhante.

Neste estudo, evidenciou-se a marcação apenas do núcleo celular nos casos positivos, demonstrando o padrão de qualidade obtido.

Na análise estatística da imunomarcação do Ki-67 no bócio colóide da tireóide, destaca-se o coeficiente de correlação entre o índice de marcagem e a densidade óptica do Ki-67 $(0,78)$, com rejeição da hipótese nula $(p<0.001)$, onde se observa proliferação celular com variação da densidade óptica que apresenta maior grau de heterogeneidade. O padrão de normalidade apresentado pelo bócio colóide nos dois parâmetros utilizados, demonstra que a proliferação dele segue com baixa resposta proliferativa e padrão não homogêneo, sendo compatível com o comportamento não agressivo característico.

Para o bócio colóide, o coeficiente de correlação entre o índice de marcagem e a densidade ótica foi igual a 0,78 . O resultado do teste estatístico indicou a rejeição da hipótese que não existe correlação $(p<0,001)$. Sendo assim, pode-se afirmar que existe associação positiva e significativa entre o índice de marcagem e a densidade ótica.

Na análise da imunomarcação do Ki-67 no carcinoma papilífero, foi demonstrado que não houve correlação significativa entre o índice de marcagem e a densidade óptica com p<0,572 e coeficiente de correlação de 0,18. Os índices demonstram que há proliferação celular e que a densidade óptica é particularmente homogênea na amostra. No entanto, a atividade proliferativa no tecido tiroideano normal e em carcinomas bem diferenciados da tireoide é muito baix ${ }^{6}$. 
Os histogramas proliferativos do carcinoma papilífero apresentam tendência com maior resposta proliferativa quando aumenta o grau de indiferenciação celular?

Tendo uma resposta próxima aos achados nos resultados, Erickson et al. ${ }^{8}$, observou em estudos com a proteína Ki-67 em carcinoma foliculares da tireóide com metástase que tinham alto índice de marcagem de Ki-67, que o Ki-67 pode ajudar na predição de metástase. A proteína Ki-67 separa carcinomas anaplásicos da tireóide de outros grupos. Assim como separa carcinomas foliculares de adenomas foliculares. Essas proteínas do ciclo celular podem ser úteis na distinção entre neoplasias foliculares malignas e lesões benignas.

A análise dos resultados apresentados demonstra que tanto o bócio colóide quanto o carcinoma papilífero da tireóide expressam através da imunomarcação do Ki-67 resposta proliferativa, sendo que a resposta do carcinoma papilífero é maior e mais homogênea do que a do bócio colóide. Comportamento esse que demonstra maior grau de agressividade do carcinoma papilífero da tireóide em relação ao bócio colóide da tireóide, estando esse fator diretamente ligado a sua característica de malignidade e disseminação metastática9 ${ }^{\text {. }}$
A expressão citofotométrica quantitativa do fator de proliferação celular Ki-67 no carcinoma da tireóide e no bócio multinodular foram estatisticamente relevantes. Através da variável índice de marcação que indica teoricamente proliferação celular no tecido testado. Porém, se fazem necessários novos estudos de imunoistoquímica com a proteína p53, pois o acúmulo dessa proteína está relacionada com a fase $\mathrm{GO}$ do ciclo celular $^{4}$. Por isso há precaução para o uso do Ki-67 em estudos onde as células expressam p53 e p21, pois elas podem estar Ki-67 positivas sem atividade proliferativa. Apesar dessas observações a literatura descreve o Ki-67 como um excelente marcador para células tumorais, por isso tem sido muito usado como ferramenta no diagnóstico de câncer e o curso da neoplasia.

Em conclusão, a expressão citofotométrica do Ki67 no bócio colóide teve índice médio de marcação de 13,92\% e densidade óptica média de 36,43; a expressão citofotométrica do Ki-67 no carcinoma papilífero teve índice médio de marcação de 38,29\% e densidade óptica média de 48,07\%; há maior proliferação celular no carcinoma papilífero em comparação com o bócio colóide na expressão do Ki-67.

\title{
A $B$ S S T R A C
}

\begin{abstract}
Objective: To compare the cytophotometric quantitative expression of Ki-67 cellular proliferation factor in the colloid goiter with papillary carcinoma of the thyroid. Methods: The protein Ki-67 was studied with immunohistochemistry in 20 cases of papillary carcinoma of the thyroid and 12 cases of colloid goiter. The immunomarked cell nuclei were quantified through the software SAMBA $4000 \AA$ and analyzed by software IMMUNO $\Theta$, considering variables index marker and optical density. The coefficient of the Spearman rank correlation and the non-parametric test of Mann-Whitney wre estimated. Results: There is significant difference between the goiter colloid and the papillary carcinoma of the thyroid in Ki-67 measurements, being bigger in papillary carcinomas. No difference was found in optical density. The correlation coefficient between the index marker and the optic density was 0,78. In colloid goiter, there was positive and significant association between the index marker and the optic density. For the papillary carcinoma of the thyroid the correlation between index marker and optic density was 0,18 $(p=0,572)$. There was no association between the index marker and the optic density in the carcinoma papillary of the thyroid. Conclusion: The cytophotometric expression of the Ki-67 showed higher cellular proliferation in the papillary carcinoma of the thyroid in comparison with in the colloid goiter.
\end{abstract}

Key words: Immunohistochemistry. Cell proliferation. Goiter nodular. Thyroid neoplasms.

\section{REFERÊNCIAS}

1. Matsuo SE, Martins L, Leoni SG, Hajjar D, Ricarte-Filho JCM, Ebina $\mathrm{KN}$ et al. Marcadores biológicos de tumores da tireóide. Arq Bras Endocrinol Metab. 2004; 48(1):115-25.

2. Endl E, Gerdes J. Posttranslational modifications of the $\mathrm{KI}-67$ protein coincide with two major checkpoints during mitosis. J Cell Physiol. 2000; 182(3):371-80

3. Califice S, Castronovo V, Bracke M, Brûle F. Dual activities of galectin-3 in human prostate câncer: tumor suppression of nuclear galectin-3 vs tumor promotion of cytoplasmic galectin-3. Oncogene. 2004; 30(45):7527-36.

4. Sholzen T, Gerdes J. The Ki-67 protein: from the known and the unknown. J Cell Physiol. 2000; 182(3):311-22.

5. Müller-Höker J. Immunoreactivity of P53, Ki-67 and $\mathrm{BCl}-2$ in oncociytic adenomas and carcinomas of thyroid gland. Hum Pathol. 1999; 30(8):926-33.

6. Schlumberger M, Fileu S, Hay LD. Nontoxic goiter and thyroid neoplasia. In: Williams RH, Larsen PR, editors. Williams's textbook of endocrinology. 10 $10^{\text {th }}$ ed. Philadelphia: Saunders; 2003. cap. 13.

7. Tasca C, Stefaneau L. Cytology and cytophotometry in thyroid diseases. Acta Histochem. 1977; 60(2):261-72
8. Erikson LA, Jin L, Wollan PC, Thompson GB, Heerden J, Lloyd RV. Expression of p27(Kip1) and $\mathrm{Ki}-67$ in benign and malignant thyroid tumors. Mod Pathol. 1998; 11(2):169-74.

9. Yoshida A, Kamma H, Asaga T, Masuzawa C, Kawahara S, Mimura T et al. Proliferative activity in thyroid tumors. Cancer. 1992; 69(10):2548-52.

Recebido em 02/10/2008

Aceito para publicação em 08/12/2008

Conflito de interesse: nenhum

Fonte de financiamento: nenhuma

\section{Como citar este artigo:}

Souza GD, Czeczko NG, Moreira H, Ribas Filho JM, Mafafaia O, Czeczko LEA, Thiele ES, Aguiar LRF. Expressão citofotométrica do fator de proliferação celular ki-67 no bócio colóide e no carcinoma papilífero da tireóide. Rev Col Bras Cir. [periódico na Internet] 2009; 36(2). Disponível em URL: http://www.scielo.br/rcbc

\section{Endereço para correspondência:}

E-mail: Ipem@evangelico.org.br 